\title{
Evaluating the effectiveness of the Motivating Teens To Sleep More program in advancing bedtime in adolescents: a randomized controlled trial
}

Jamie Cassoff ${ }^{1} 2^{*}$, Florida Rushani $^{1}$, Reut Gruber ${ }^{2}$ and Bärbel Knäuper ${ }^{1}$

\begin{abstract}
Background: Sleep restriction is a prevalent issue for adolescents and has been associated with negative cognitive, emotional, and physical health (e.g., poor attention, depressed mood, obesity). Existing sleep promotion programs are successful in improving adolescents' sleep knowledge but not sleep behaviour. The aim of this randomized controlled trial is to evaluate the effectiveness of Motivating Teens to Sleep More program - a sleep promotion program with embedded sleep education that combines three approaches: motivational interviewing style, tailoring activities, and stage-based intervention - as compared to a sleep education only control in motivating adolescents to go to bed earlier leading to prolonged sleep duration.
\end{abstract}

Methods/Design: The Motivating Teens to Sleep More study will be conducted with adolescents at a Montreal high school. Half of the participants will be randomly assigned to the Motivating Teens to Sleep More program condition and the other half to the sleep education control condition. Each condition will consist of four 1-hour sessions spanning four consecutive weeks. Bedtime will be assessed by sleep logs completed for a week prior to the start of the program, in the middle of the program and following the program. Sleep onset and total sleep time will be assessed by actigraphy for one week prior to the start and following the program.

Discussion: The Motivating Teens to Sleep More program is a novel intervention that contributes theoretically to the field of pediatric sleep by merging three approaches to motivate normally developing adolescents to adopt earlier bedtimes. Should the program be successful in advancing bedtimes and increasing total sleep time, the study would offer insights in how to design effective motivational sleep promotion programs for adolescents, which can potentially improve adolescent health and well-being.

Trial registration: ISRCTN19425350.

Keywords: Adolescent sleep, Motivation, Sleep promotion, Sleep restriction, Bedtime

\section{Background}

Evidence indicates that sleep restriction (the elimination of sleep from one's needed amount for optimal performance) is particularly prevalent in adolescent populations (Reynolds and Banks 2011). While experts state that the optimal amount of sleep in adolescence is 9.2 hours per

\footnotetext{
* Correspondence: jamie.cassoff@mail.mcgill.ca

${ }^{1}$ Health Psychology Laboratory, Department of Psychology, McGill University, Stewart Biology Building, 1205 Dr. Penfield Avenue, Montreal, QC H3A 1B1, Canada

${ }^{2}$ Attention, Behaviour and Sleep Laboratory, Douglas Mental Health University Institute, 6875 LaSalle Boulevard, Verdun, QC H4H 1R3, Canada
}

night (Carskadon et al. 1980; Iglowstein et al. 2003; Mercer et al. 1998), a recent poll by the National Sleep Foundation found that $61 \%$ of adolescents are not getting this recommended amount of sleep (National Sleep Foundation 2011). Delayed bedtime is the primary cause of insufficient sleep duration in this population, i.e. adolescents go to bed too late. In a longitudinal study (Iglowstein et al. 2003) comparing the sleep timing of three birth cohorts (1974, 1979 and 1986) until the age of 16 years old, it was found that adolescents' sleep duration was lowest in the most recent decades. The 
decreased sleep duration was attributed to later and later bedtimes but unchanged wake up times. The latter finding can likely be attributed to set wake up times for school in the morning but increasing distractions at nighttime including technology, social life and extracurricular activities. Further, adolescence is associated with a delayed sleep phase resulting in an endogenous preference for much later bedtimes than children and adults. Sleep restriction due to late bedtimes is associated with poor attention, deficits in academic achievement, depressed mood, psychoactive substance use, car accidents, and obesity in adolescents (Curcio et al. 2006; Dewald et al. 2010; Durmer and Dinges 2005; Knutson et al. 2007). Dewald-Kaufmann et al. (2013) have shown that gradual advancement of adolescent bedtime is a feasible approach and is associated with increased total sleep duration. Given the negative impact of sleep restriction on adolescent health, widespread efforts to create sleep interventions aimed at advancing bedtime in order to increase sleep duration are needed.

Existing adolescent sleep promotion programs mainly focus on sleep education and have indeed been found to be successful in enhancing adolescent knowledge about sleep (Bakotić et al. 2009; Cain et al. 2011; Cortesi et al. 2004; Moseley and Gradisar 2009) but the programs for which sleep behaviour in addition to knowledge outcomes has been evaluated find insignificant improvements in sleep behavior (Cain et al. 2011; Moseley and Gradisar 2009). Adolescents may not be motivated to go to bed earlier as the behavior change implies less time for leisure, extracurricular activities, communicating with friends, etc. (Cassoff et al. 2013). This lack of motivation might perhaps account for the inefficacy of current programs in changing adolescents' bedtime.

Thus, future adolescent sleep research should be done to investigate the role of adolescent motivation in the development and implementation of sleep promotion programs (Cassoff et al. 2013). The focus on solely enhancing sleep knowledge rather than also addressing motivational readiness to improve sleep behaviour may explain why efforts to reduce adolescent sleep restriction remain mostly unsuccessful. Therefore, we developed the Motivating Teens to Sleep More (MTSM) program. It aims to fill the gaps of previous research by enhancing motivation to go to bed earlier in a way that is congruent with adolescent developmental characteristics. The MTSM program aims to enhance motivation by incorporating three main active ingredients, namely a motivational interviewing (MI) style, a stage-based intervention approach and a tailored intervention approach.

\section{Motivational interviewing}

Motivational Interviewing is a collaborative, personcentered counseling style that elicits and strengthens motivation for change (Miller and Rollnick 2002). It is based on unique principles including expressing empathy towards the client, encouraging the client to be autonomous rather than assuming an authoritarian position that imposes ideas on them, rolling with resistance (i.e. not confronting and challenging the client when they make resistant statements), and helping the client realize that there is a discrepancy between their current maladaptive behaviour and their life goals and values (Baer and Petersen 2002). MI has been found to be effective in motivating behaviour change especially when used in conjunction with another intervention (Hettema et al. 2005). As such, the effects of MI in motivating advanced bedtime may be enhanced when applied with stage-based and tailored intervention components. Additionally, its non-confrontational nature encourages adolescents to make autonomous decisions to advance their bedtime. This is fitting with the tendency for adolescents to rebel against authority figures as well as the increase in independent decision-making associated with the adolescence developmental period (Elliott and Feldman 1990). The interaction between the interventionist and participant will be in the form of a conversation rather than authoritarian instruction, which is characteristic of the MI style. Further, due to its efficacy in motivating adolescents to make positive behavioural changes in health areas including smoking, alcohol use, and diet, MI has recently been proposed as a potentially suitable intervention for promoting healthy sleep habits in adolescent populations (Gold and Dahl 2010). Thus far, the effects of MI on adolescent sleep behaviour have been evaluated in the school context (Cain et al. 2011), where motivational sessions were offered to groups of students at once. Although motivation to improve sleep habits was increased following the intervention, no differences in sleep behaviour were found. The current study will investigate MI delivered in a one-on-one context because the principles of MI are best suitable for one-on-one programs, especially when targeting complex behaviours such as sleep (Britt et al. 2004; Rollnick and Miller 1995).

\section{Tailored intervention}

Tailored interventions are created by assessing personal data related to the particular health behaviour in order to determine the most appropriate information and/or strategies to meet the individual's unique needs (Kreuter 2003). This information and/or strategies are then delivered to the person in the intervention. Personalizing information or tailoring messages for each individual have been shown to be more effective than presenting generic information in engaging individuals, building their selfefficacy and improving health behaviours (Noar et al. 2007; Sohl and Moyer 2007). There is growing evidence for the use of tailoring in complex health behaviour interventions (e.g. for nutrition (Hoelscher et al. 2002), 
exercise (Salmon et al. 2007) etc.). Tailored interventions are most effective with complex health behaviours that involve multiple actions (Kreuter 2003). Putting oneself to bed can be considered a complex behaviour because it encompasses multiple actions including employing sleep hygiene behaviours that occur before bedtime, ignoring a multitude of distractions that occur at bedtime, and physically putting oneself into bed. Due to the complexity of bedtime and the effectiveness of tailored intervention with complex health behaviours, the current sleep promotion program will be tailored. Specifically, the MTSM program will be 'tailored' to important determinants of sleep and to other personal characteristics of the participant that could be helpful in further enhancing the effectiveness of the activities used in each session. While the stage-based part of the sleep promotion program will customize content depending on the stage of change, that is, individuals similar in their readiness to change levels will receive similar strategies; the tailored part of the intervention will further customize intervention activities to personal characteristics including personality, goals, values, and other determinants of sleep behaviour change. Adolescents may respond well to tailored interventions because it allows for the development of personal and direct intervention content based on elements such as likes/dislikes, needs, and current health behaviours or behavioural intentions. For example, because the MTSM program is tailored to the needs and preferences of each participant, the extent to which parents are involved varies between participants. There is ample opportunity for the adolescent to express how his/her parents could support his/her decision to go to bed earlier. However, in some cases, the adolescent expresses that a sibling or friend would be better suited as his/her support system.

One-on-one interventions have been developed to improve the sleep patterns of adolescents diagnosed with delayed phase sleep disorder (Gradisar et al. 2011; Saxvig et al. 2013; Wilhelmsen-Langeland et al. 2013). Results indicate the treatments involving one-on-one cognitive behavioural therapy (CBT) aimed at motivating the individual in addition to a chronobiology-related treatment (e.g. bright light therapy, melatonin administration) result in more sustained advancements in circadian rhythm alignment than protocols without CBT (Gradisar et al. 2011). To our knowledge, tailored motivational interventions have yet to be applied in the context of normally developing adolescents' sleep.

\section{Stage-based intervention}

Stage-based interventions, grounded in the Transtheoretical Model of Behaviour Change (TTM), deliver stagetailored content that is aimed at promoting movement through stages of change and leading to improvements in health behaviour, decisional balance, and self-efficacy (Prochaska and Velicer 1997). The majority of the current study will be modeled according to a stagebased intervention as the program will involve first identifying the readiness to advance bedtime of the adolescent and then identifying the corresponding processes of change that the TTM proposes to be necessary in enabling and facilitating stage advancement (see Table 1). Once the processes are identified, the interventionist will employ activities (found efficacious in previous sleep studies) in order to boost those processes, with the goal of enhancing motivation and readiness to advance bedtime. Stage-based interventions have been found to be effective in the cessation of maladaptive behaviours such as smoking, cocaine abuse, and delinquent behaviour, and in the acquisition of positive behaviours such as safer sex practices, sunscreen use, and regular exercise in adolescents (Prochaska and Prochaska 2010; Riemsma et al. 2003; Weinstock et al. 2000). This is relevant for the current intervention because going to bed earlier, like the aforementioned health behaviours, is a behaviour that adolescents tend to be unmotivated for. Another reason why a stage-based intervention is fitting for a sleep promotion program is because the activities used to boost TTM processes (i.e. to progress an individual through the stages of change) overlap significantly with intervention strategies currently used to promote adolescent sleep (see Table 1). All existing adolescent sleep promotion programs incorporate sleep knowledge (Bakotić et al. 2009; Bootzin and Stevens 2005; Cain et al. 2011; Cortesi et al. 2004; De Sousa et al. 2007; Moseley and Gradisar 2009). Some have used strategies including cognitive restructuring (Bootzin and Stevens 2005; Cain et al. 2011; Moseley and Gradisar 2009), mindfulness exercises (Bootzin and Stevens 2005), stimulus control (Cain et al. 2011; De Sousa et al. 2007; Moseley and Gradisar 2009), role playing, goal setting (Cain et al. 2011), cues to action (De Sousa et al. 2007), and personal action exercises (Moseley and Gradisar 2009). Strategies that have demonstrated to be effective in previous sleep promotion programs will be incorporated in the current intervention. Please see Table 1 for a detailed explanation of how the activities used in previous sleep promotion programs will be integrated within the Motivating Teens to Sleep More program. To our knowledge, stage-based interventions have yet to be applied in the context of adolescent sleep.

\section{The current study}

The objective of this trial is to compare improvements in sleep habits immediately following the completion of the program and at 3-month and 6-month follow-up periods in adolescents receiving the Motivating Teens to 
Table 1 The stages of change and corresponding TTM processes, MTSM activities, variables measured at baseline, and integration with previous adolescent sleep interventions

\begin{tabular}{|c|c|c|c|c|}
\hline Stage of change & Example of TTM process & $\begin{array}{l}\text { Example of a MTSM program } \\
\text { activity designed to enhance } \\
\text { the process }\end{array}$ & $\begin{array}{l}\text { Variables measured } \\
\text { at baseline that } \\
\text { allow to tailor this } \\
\text { activity }\end{array}$ & $\begin{array}{l}\text { Integration with previous } \\
\text { sleep promotion programs }\end{array}$ \\
\hline \multirow[t]{4}{*}{ Precontemplation } & \multirow{4}{*}{$\begin{array}{l}\text { Consciousness raising: } \\
\text { Raising awareness about } \\
\text { sleep deprivation }\end{array}$} & \multirow{4}{*}{$\begin{array}{l}\text { Sleep education: Discussing with } \\
\text { the adolescent in an interactive way } \\
\text { about sleep-related facts and conse } \\
\text { quences related to sleep deprivation. }\end{array}$} & · Knowledge & \multirow{4}{*}{$\begin{array}{l}\text { Sleep hygiene education } \\
\text { (Bakotić et al. 2009; Bootzin } \\
\text { and Stevens 2005; Cain et al. } \\
\text { 2011; Cortesi et al. 2004; } \\
\text { Moseley and Gradisar 2009) }\end{array}$} \\
\hline & & & - Risk perception & \\
\hline & & & - Information needs & \\
\hline & & & - Personal values & \\
\hline \multirow[t]{2}{*}{ Contemplation } & \multirow{2}{*}{$\begin{array}{l}\text { Self-reevaluation: } \\
\text { Examining how one thinks } \\
\text { and feels about oneself } \\
\text { with respect to the current } \\
\text { behaviour }\end{array}$} & \multirow{2}{*}{$\begin{array}{l}\text { Decisional balance: Eliciting from } \\
\text { the adolescent thoughts on the pros } \\
\text { and cons of going to bed earlier, } \\
\text { while the interventionist highlights } \\
\text { and elaborates on statements that } \\
\text { reveal discrepancy between current } \\
\text { sleep behaviour and future goals } \\
\text { and values, thus encouraging } \\
\text { behaviour change. }\end{array}$} & $\begin{array}{l}\text { - Attitudes towards } \\
\text { sleep }\end{array}$ & \multirow{2}{*}{$\begin{array}{l}\text { Cognitive restructuring (Bootzin } \\
\text { and Stevens 2005; Cain et al. } \\
\text { 2011; Moseley and Gradisar, } \\
\text { 2009) }\end{array}$} \\
\hline & & & Personal values & \\
\hline Preparation & $\begin{array}{l}\text { Dramatic relief: Experiencing } \\
\text { and expressing feelings to } \\
\text { help motivate change }\end{array}$ & $\begin{array}{l}\text { Role playing and personal } \\
\text { testimonies: Improvising a situation } \\
\text { where the adolescent focuses on the } \\
\text { consequences of delayed bedtime in } \\
\text { his/her life and then relieving this } \\
\text { evoked emotional discomfort by } \\
\text { providing personal testimonies of } \\
\text { individuals who have successfully } \\
\text { changed their bedtime and enjoy the } \\
\text { positive ramifications of that change. }\end{array}$ & - Self-efficacy & $\begin{array}{l}\text { Sleep-related role playing } \\
\text { (Cain et al. 2011; Moseley } \\
\text { and Gradisar 2009) }\end{array}$ \\
\hline \multirow[t]{2}{*}{ Action } & \multirow{2}{*}{$\begin{array}{l}\text { Self-liberation: Choosing } \\
\text { to act or belief in ability to } \\
\text { go to bed earlier }\end{array}$} & \multirow{2}{*}{$\begin{array}{l}\text { Sleep hygiene action plan: Offering } \\
\text { the participant an agenda setting chart } \\
\text { (please see Figure 2) from which to } \\
\text { autonomously choose a sleep hygiene } \\
\text { behaviour to improve. }\end{array}$} & - Personal values & \multirow{2}{*}{$\begin{array}{l}\text { Personal action }{ }^{34} \text {, goal setting } \\
\text { exercises (Cain et al. 2011) }\end{array}$} \\
\hline & & & $\begin{array}{l}\text { - Sleep hygiene } \\
\text { behaviour }\end{array}$ & \\
\hline Maintenance & $\begin{array}{l}\text { Stimulus control: Avoiding } \\
\text { or countering stimuli that } \\
\text { make the adolescent go to } \\
\text { bed late }\end{array}$ & $\begin{array}{l}\text { Stimulus control exercise: } \\
\text { Presenting the adolescent with } \\
\text { instructions on ways to: (i) remove } \\
\text { cues from the environment that } \\
\text { promote late bedtimes, and (ii) add } \\
\text { prompts for earlier bedtimes. }\end{array}$ & $\begin{array}{l}\text { - Social influence } \\
\text { (identifying positive } \\
\text { and negative } \\
\text { influences) }\end{array}$ & $\begin{array}{l}\text { Stimulus control (Bootzin and } \\
\text { Stevens 2005; Cain et al. 2011; } \\
\text { Moseley and Gradisar 2009) }\end{array}$ \\
\hline
\end{tabular}

Note. The activity included in Table 1. Corresponding to each stage of change is one of several examples. A single activity may be suitable for multiple stages of change. Furthermore, the process by which one proceeds through the stages of change is fluid. Although all participants included in the study report being in the contemplation stage of change during the screening phase, they may revert back to the precontemplation stage at a later time in the intervention.

Sleep More program, an individualized sleep promotion program (embedded with a sleep education component) aimed at enhancing motivational readiness to go to bed earlier in comparison to adolescents in a one-on-one sleep education only condition. The active sleep education control group will be used to parse the beneficial effect of one-on-one aspect of the intervention from the beneficial effect of stage-based, tailored sleep education and motivational techniques (i.e. the active ingredients of the MTSM) in regard to these sleep-constructs. The effects of the Motivating Teens to Sleep More Program will be assessed according to the following bedtimerelated constructs: (1) time that the adolescents go into bed (i.e. bedtime), (2) time that the adolescents fall asleep (i.e. sleep onset), and (3) duration for which the adolescents are asleep (i.e. total sleep time).

\section{Methods}

\section{Design}

The current study is a parallel randomized controlled trial in which the experimental group receives the oneon-one MTSM program including tailored motivational strategies and sleep education as a component within the program and the control group receives one-on-one sleep educational sessions only.

\section{Participants}

The participants will be high school students aged 12 18 years old. Previous research (Treasure 2004) suggests that the effect sizes of interventions based on adaptations of motivational interviewing as well as manualized versions of motivational interviewing have a small effects (i.e. $d=0.25$ ). Assuming an effect size of 0.25 , the 
required number of participants was calculated for a power level of .80 and an alpha level of .05. Given the within subject design with sleep measured at pre, post and 6-months follow-up, power analyses revealed that a sample size of 30 adolescents would be required. Inclusion criteria will consist of having a late bedtime (i.e. a bedtime that results in less than eight hours of sleep on a school-night) and reporting being in the contemplation stage of change (i.e. considering advancing bedtime within the next 6 months). Exclusion criteria will consist of any sleep disorder and/or medical and mental condition that interferes with sleep. The screening procedure for medical and mental conditions that interfere with sleep is that a parent of the child responds to the following question in an online survey: "Please indicate whether your child has been suffering from any of the following within the past 12 months." If the parent chooses "asthma attacks," and/or "skin condition," and/ or "Attention Deficit Disorder (ADD)," and/or "Attention Deficit and Hyperactivity Disorder (ADHD)," and/ or "conduct disorder," and/or "anxiety disorder," and/or "depression" then the child is in ineligible to participate. The screening procedure for sleep disorders is that the parent and children together respond to the Sleep Disorder Inventory for Students - Adolescent Version (SDIS-A). As per the scoring instructions for this instrument, if the overall score is above 104, then the child is ineligible to participate.

\section{Procedure}

The parent of an interested adolescent will contact the research team at which time he/she will be invited to complete an online parental consent form followed by a screening questionnaire on sleep, medical and psychiatric disorders. We will sequentially assign each participant a unique personal identifier to be entered into the screening questionnaire. Once the parent completes the form to screen for whether his/her child has a sleep disorder and if his/her child remains eligible (his/her child will be contacted (via email and/or telephone call) to complete the rest of the screening process. The remainder of the screening process will consist of the adolescent completing an online questionnaire to assess his/ her stage of change and bedtime. Should the participant be ineligible to participate both he/she and his/her parent/legal tutor will be notified. If the participant is eligible to participate, the RA will contact the participant and ask him/her to complete the baseline questionnaire, which will occur online at a time of his/her convenience. The baseline questionnaire will assess variables that are important in individualizing the sessions including personal values, attitudes towards sleep, confidence in ability to change sleep habits, sleep-related social influences, and sleep knowledge, risk perception, and cues to action.
At this time, the RA will also schedule the first session and provide the participant with general information about the study including the location, duration and number of the sessions. The first page of the baseline questionnaire will contain an assent text that will describe the study according to developmentally appropriate reading and comprehension levels of the youngest age group (12 years old). Participants will be instructed that by clicking "I agree" they are providing assent and agree to participate in the study.

Students will meet with the RA at their school (1-week before the start of the sessions) to be provided with an actiwatch and instructions for using it for seven nights in a row. An actiwatch is a small watch-like device worn on the wrist. It assesses sleep-wake patterns through body movement during the night. They will also be asked to fill in a sleep log indicating their bed and wake times, and napping schedule during this period. After one week, the participants will return the actiwatch and the sleep log sealed in an envelope (provided by the RA to ensure confidentiality) to their school's administrative office to be picked up by the RA, at which point the sessions will begin. The same procedure will take place during actigraphy data collections after the sessions.

All sessions will be one hour in duration and will take place once a week for four consecutive weeks. Two graduate students in psychology will each administer half of the sleep education sessions and half of the MTSM program sessions. Questionnaires assessing sleep behaviour will be completed immediately following each session and at three and six months following program completion.

\section{Randomization}

We will employ a randomization process where the participant will be allocated to either group A (MTSM program with an embedded sleep education component) or group B (Sleep education sessions only). A randomization sequence will be created using a secure online randomization service (www.randomization.com). The randomization sequence will be assigned on a 1:1 ratio to the intervention and control groups. Only the research team will have access to the online randomization scheme. Please see Figure 1 for a description of the study flow.

\section{Control group: sleep education}

Each sleep education session will be one-on-one (interventionist and participant) and will consist of the interventionist presenting information concerning different aspects of sleep. In session 1, the interventionist will teach the participant about sleep in general, in session 2 about teenagers and sleep, in session 3 about sleep disorders, and in session 4 about sleep hygiene. Although the participant will be invited to ask questions if they do not understand, the responses offered by the interventionist 


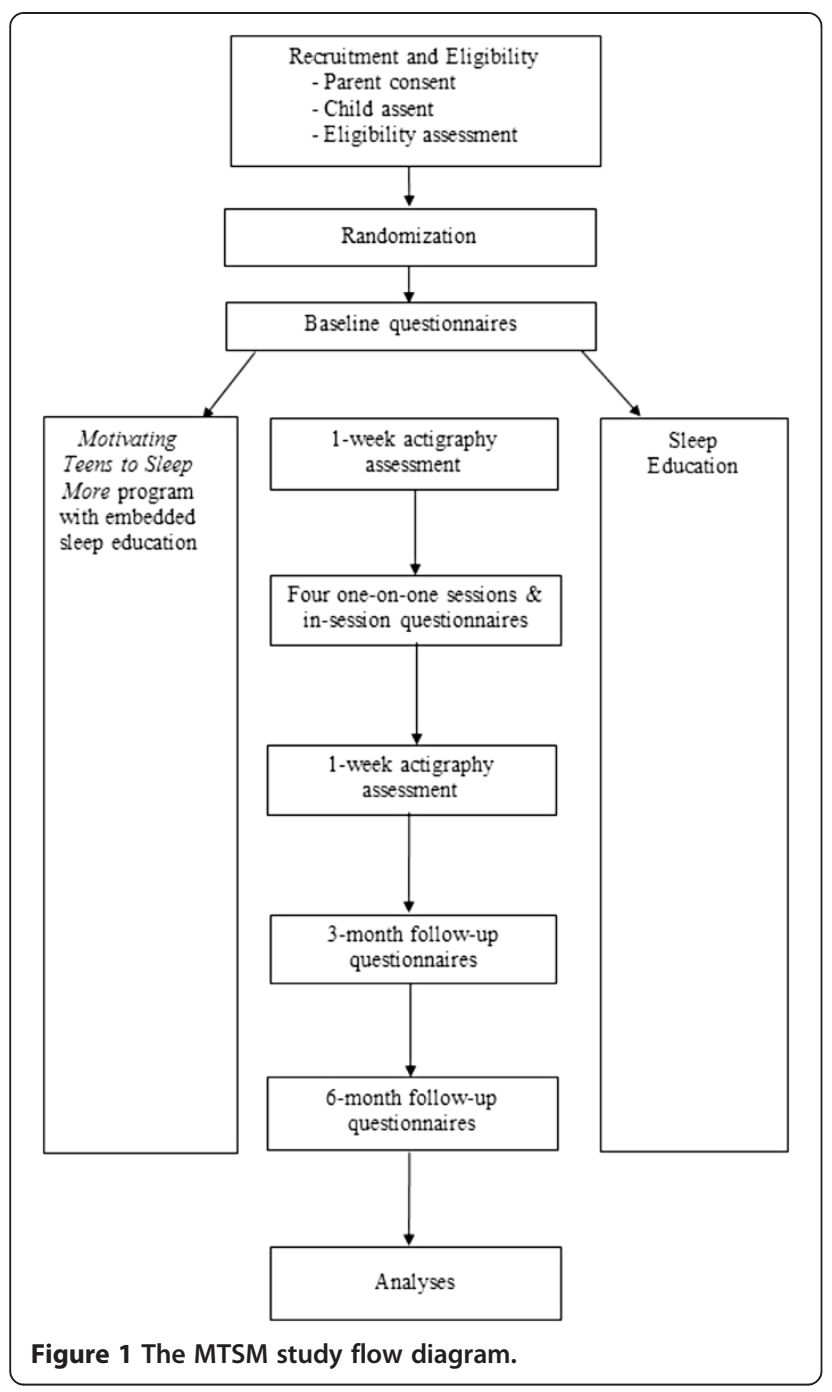

will be directly related to content clarification and will not involve any personalized or motivational strategies.

\section{Experimental group: MTSM program with embedded sleep education}

The difference between the sleep education only sessions and the MTSM program with an embedded sleep education component will be that in the latter the interventionist will not only teach about sleep but will also use activities that are matched to the participant's readiness to change their bedtime and are aimed to increase their motivation to go to bed earlier. Specifically, the interventionist will choose the activities to conduct in the session depending on the current readiness to advance bedtime of the participant. Sleep education will be embedded in the program in that participants who are unfamiliar with particular aspects of sleep will be provided with the information that they are missing. However, this will not be provided in a 'one size fits all' format as is the case in the sleep education sessions. Rather, participants will be provided with sleep education in a way that is tailored to what they currently do and do not know. For example, if the participant is aware of the consequences of sleep on their mood but not the consequences of sleep on their academic performance (as concluded by result on the baseline questionnaire), the interventionist will provide him/her with the information they are missing by discussing the potential negative effects of sleep deprivation on attention and behaviour in school. Due to the inclusion criterion of being in the contemplation stage of change, at the start of the first session the activities used will be similar across participants. All activities that could be further tailored to individual characteristics of the participant will be done so in a way that is standardized in the study manual. For example, during the sleep hygiene action plan activity of choosing a sleep hygiene behaviour to improve (please see Figure 2), the interventionist will congratulate the adolescent regarding sleep hygiene behaviours that he/she already does and will only suggest that he/she chooses a sleep hygiene behaviour needing improvement. Sleep hygiene behaviour information will be provided in the baseline questionnaire by each participant. Finally, all of the sessions will be conducted in a MI style. A MI style will consist of expressing empathy towards the adolescent, encouraging the adolescent to be autonomous rather than assuming an authoritarian position that imposes ideas on them, rolling with resistance (i.e. not confronting and challenging them when they make resistant statements), and helping the adolescent realize that there is a discrepancy between their current maladaptive behaviour and their life goals and values. A specific bedtime will not be prescribed for the teens because this would go against the motivational interviewing approach. Rather, the interventionist will work together with the participants to set a bedtime goal that is realistic based on the teen's personal schedule and level of motivation. Further, although a set bedtime goal is created with the teens in the first session, the participant is encouraged by the interventionist to update this goal (by either making their bedtime goal earlier or later) depending on their progress throughout the program. Reminders for the interventionist to engage in motivational interviewing congruent behaviours are present throughout the study manual.

\section{Fidelity assessment}

We will measure the fidelity of the intervention by 1 ) conducting standardized training sessions for the interventionists consisting of a 2-day training on the study procedures, the MTSM program and the sleep education program as well as over 20 hours of clinical training some of which were delivered by members of the Motivational Interviewing Network of Trainers (MINT) and 2) by audio-recording the sessions to be listened to by two 


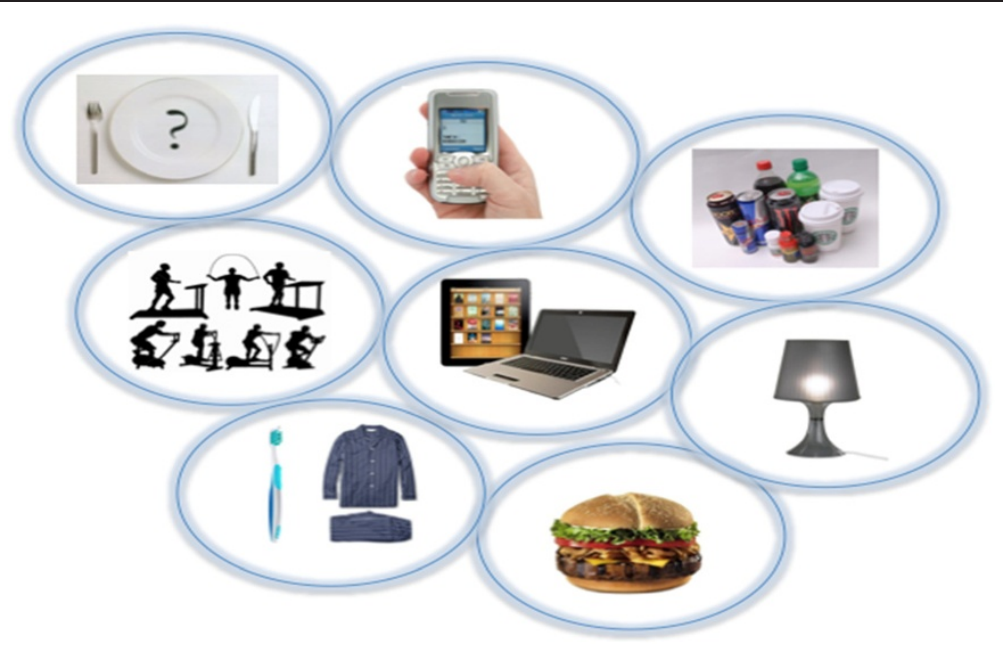

Figure $\mathbf{2}$ The sleep hygiene action plan activity as per the MTSM study manual.

RAs who will complete assessments measuring how adherent the interventionist was to the study manual and procedures. We created the fidelity assessment for the current study and they consist, in part, of the Motivational Interviewing Treatment Integrity Code (Moyers et al. 2010).

\section{Measures}

Bedtime

Bedtime is the time the adolescent will report on the sleep logs going into bed at night.

\section{Sleep onset and total sleep time}

Sleep onset and total sleep time will be assessed through actigraphy assessments in conjunction with daily sleep logs for the week prior and the week after the four sessions. Actigraphy is a method used to measure sleepwake patterns through body movement (Littner et al. 2003) by recording data from accelerometers several times per second. These computerized wristwatch-like devices collect data generated by movements. Actiwatches are not intrusive and can record sleep timing without affecting the child's bedtime routine. Actigraphy has been validated against polysomnography with agreement rates for minute-by-minute sleep-wake identification $>90 \%$ (Ancoli-Israel et al. 2003). One-minute epochs will be used to analyze actigraphic sleep data. The bedtime and wake time reported in the sleep logs will be used as the start and end times for the current analyses. For each 1-min epoch, the total sum of activity counts will be computed. If they exceed a threshold (threshold sensitivity value $=$ mean score in active period/45), then the epoch will be considered waking. The first time it falls below that threshold will be considered "sleep onset". The actigraphic sleep measures to be used in this study include parameters pertaining to actual time spent asleep during the night (i.e. total sleep time) and the time in which the participant falls asleep (i.e. sleep onset).

\section{Readiness to go to bed earlier}

Readiness to go to bed earlier will be assessed by two measures. First, a readiness ruler (LaBrie et al. 2005) adapted to sleep will be completed such that participants will indicate on a 10-point ruler how they presently feel about going to bed earlier. Anchors included "Never think about my bedtime," Sometimes I think about advancing my bedtime," "I have decided to advance my bedtime," "I am already trying to advance my bedtime," "My bedtime has changed, I now go to sleep earlier." The readiness ruler has shown good criterion validity with self-reported behaviour in the areas of condom use and alcohol consumption (LaBrie et al. 2005). The readiness ruler will be completed at baseline, after each session and at follow-up assessments. The second measure will be the 11-item Readiness to Change Questionnaire (RTCQ; Rollnick et al. 1992) adapted to sleep. Precontemplation, contemplation, and action were each represented by four items measured on a 5-point scale $(-2=$ strongly disagree to $+2=$ strongly agree). Stage of change as measured by the RTCQ has been validated as a good predictor of health behaviours (Heather et al. 1993). A single indicator of readiness to change will be calculated by adding up the scores for the contemplation and action questions and the reverse scores for the preparation questions. Stage of change, as measured by the RTCQ has been validated as a good predictor of health behaviours (Heather et al. 1993).

\section{Sleep-related self-efficacy}

Sleep specific self-efficacy will be measured by a sleep self-efficacy questionnaire (Watts et al. 1995) modified 
to assess control over putting oneself into bed. Sample items include "How much do you feel that you have the ability to go into your bed at an earlier hour?" and "How much do you feel that the time it takes to go into your bed is under your control?" rated on a 4-point scale. Responses $(1=$ not at all to $4=$ to a great extent $)$ were modified to fit with the question stem. Another sleep self-efficacy instrument was developed for the present study. Items include the semantic structure," I can manage to get into bed at an earlier hour,... even if (barrier)," which is the rule of thumb for domain specific selfefficacy questions (Luszczynska and Schwarzer 2005). Sample barriers created for this study include "even if it meant watching less television" and "...even if it meant not seeing my friends" and are rated on a 4-point scale $(1=$ very uncertain to $4=$ very certain $)$.

\section{Attitudes towards sleep}

A decisional balance instrument will be used to assess attitudes towards sleep at baseline, at the end of each session and at follow-up assessments. The questionnaire was developed for this study based on the work of Orzech (2013), Noland et al. (2009), and Pawlak and Colby (2009), and it consists of twenty-two items: twelve items about the pros and the rest about the cons of going to bed earlier. Positive attitudes towards sleep are computed as the difference between the standardized pros scores and the standardized cons scores.

\section{Statistical analyses}

Prior to analyzing the impact of the MTSM intervention in improving adolescents' sleep behaviour, $\mathrm{t}$-tests will be run to examine to which extent randomization was successful. Specifically, it will be tested whether participants in the experimental and control group differ in the following characteristics: sleep deficit (i.e. hours of sleep by which the participants deviated from the optimal 9.2 hours of sleep), readiness to change bedtime, sleeprelated self-efficacy, and attitudes toward sleep. Variables on which experimental and control group that differ significantly will be controlled for in the subsequent analyses. Three two-way mixed ANOVAs with time (prevs. post-assessment vs. 3-month follow-up vs. 6-month) as the within-subjects factor and group (experimental vs. control) as the between-subjects factor will be performed to test whether adolescents receiving the Motivating Teens to Sleep More program differ significantly after the intervention and at three- and six-month follow-up from the adolescents receiving only sleep education in the following sleep variables: 1) bedtime, 2) sleep onset, 3) total sleep time. Significant results will be further examined by planned comparisons.

\section{Study progress}

The data collection is currently underway such that 13 participants have completed the four sessions and 4 participants have provided 3-month follow-up data. The study will be terminated once 6-month follow up data from 30 participants are collected.

\section{Ethics}

The study has obtained approval by the McGill Research Ethics Board in November 2012 (REB\# 115-0912).

\section{Discussion}

In the current study, we are evaluating the impact of a motivational sleep promotion program with an embedded sleep education component compared with sleep education only on sleep improvements in adolescents. The MTSM program is a novel intervention that merges three promising motivational initiatives - a motivational interviewing style, tailoring activities, and stage-based interventions. To the best of our knowledge, this is the first one-on-one sleep promotion program aimed at motivating normally developing adolescents to adopt earlier bedtimes.

The current study can contribute theoretically to the field of pediatric sleep by applying health behavior theories (e.g. the TTM) in conceptualizing ways in which to motivate adolescents to improve their sleep habits. The current study can also contribute practically by offering insights in how to design effective motivational sleep promotion programs for adolescents. Should the MTSM program be successful in advancing bedtimes and increasing sleep duration, it can have a positive impact on adolescent health and well-being including improved physical health (e.g. weight regulation, Lowry et al. 2012; less car accidents, Pizza et al. 2010) cognitive health (e.g. academic performance, Gruber et al. 2010, and emotional health (e.g. mood, Dahl 1999).

A limitation of the current study is the generalizability of results. Because the participants are being recruited from a private high school, our findings may not generalize to adolescents of a lower socioeconomic status. Further, it will be difficult to implement the program on a wide-scale as meeting with normally developing adolescents on a oneon-one basis is resource intensive. Should the program be successful, one way to translate the findings on a wide-scale is to implement tailored computerized sleep promotion programs. Such programs are often Internet-based and can tailor the content of health promotion materials to the specific characteristics of each participant (Rimer and Kreuter 2006). Not only is delivering the program over the Internet more feasible than in person, but it is considered an appropriate way in which to communicate with adolescents due to its accessibility and the tendency for adolescents to view the Internet as a credible source for health information (Borzekowski and Rickert 2001). 


\section{Abbreviations}

TTM: Transtheoretical model of change; MI: Motivational interviewing; MTSM: Motivating teens to sleep more.

\section{Competing interests}

The authors declare that they have no competing interests.

\section{Authors' contributions}

$\mathrm{JC}$ led the design and development of the protocol with the support of BK, RG and FR. JC led the data collection with the support of FR. JC conducted half of the intervention and control sessions. All authors were responsible for writing this manuscript. All authors read and approved the final manuscript.

\section{Acknowledgements}

Funding was provided by the Doctoral Research Allowance and Doctoral research award (Priority Announcement: Patient-Oriented Research) of the Canadian Institute for Health Research (CIHR) to the first author. We would like to thank the students, teachers and staff at Bialik High School in Montreal for their support and collaboration throughout the study, Ava-Ann Allman for delivering half of the control and experimental sessions, and Kristina Valentine, Jessica Wang, Amanda Giampersa, and Emilia Colagrosso for coordinating the scheduling of the sessions, conducting fidelity assessments and managing the database.

\section{Received: 19 July 2013 Accepted: 6 March 2014}

Published: 26 March 2014

\section{References}

Ancoli-Israel, S, Cole, R, Alessi, C, Chambers, M, Moorcroft, W, \& Pollak, C. (2003). The role of actigraphy in the study of sleep and circadian rhythms. American Academy of Sleep Medicine Review Paper. Sleep, 26(3), 342-392.

Baer, J, \& Petersen, P. (2002). Motivational interviewing for adolescents and young adults. In W Miller \& S Rollnick (Eds.), Preparing people for change. New York, NY: The Guilford Press.

Bakotić, M, Radošević-Vidaček, B, \& Košćec, A. (2009). Educating adolescents about healthy sleep: experimental study of effectiveness of educational leaflet. Croatian Medical Journal, 50(2), 174-181.

Bootzin, RR, \& Stevens, SJ. (2005). Adolescents, substance abuse, and the treatment of insomnia and daytime sleepiness. Clinical Psychology Review, 25 (5), 629-644

Borzekowski, DL, \& Rickert, VI. (2001). Adolescents, the internet, and health: issues of access and content. Journal of Applied Developmental Psychology, 22(1), 49-59.

Britt, E, Hudson, SM, \& Blampied, NM. (2004). Motivational interviewing in health settings: a review. Patient Education and Counseling, 53(2), 147-155.

Cain, N, Gradisar, M, \& Moseley, L. (2011). A motivational school-based intervention for adolescent sleep problems. Sleep Medicine, 12, 246-251.

Carskadon, Harvey, K, Duke, P, Anders, T, Litt, I, \& Dement, W. (1980). Pubertal changes in daytime sleepiness. Sleep, 2(4), 453-460.

Cassoff, J, Knäuper, B, Michaelsen, S, \& Gruber, R. (2013). School-based sleep promotion programs: effectiveness, feasibility and insights for future research. Sleep Medicine Reviews, 17(3), 207-214.

Cortesi, F, Giannotti, F, Sebastiani, T, Bruni, O, \& Ottaviano, S. (2004). Knowledge of sleep in Italian high school students: pilot-test of a school-based sleep educational program. Journal of Adolescent Health, 34(4), 344-351.

Curcio, G, Ferrara, M, \& De Gennaro, L. (2006). Sleep loss, learning capacity and academic performance. Sleep Medicine Reviews, 10(5), 323-338.

Dahl, RE. (1999). The consequences of insufficient sleep for adolescents: links between sleep and emotional regulation. Phi Delta Kappan, 80(5), 354-359.

De Sousa, IC, Araujo, JF, \& De Azevedo, CVM. (2007). The effect of a sleep hygiene education program on the sleep-wake cycle of Brazilian adolescent students. Sleep and Biological Rhythms, 5(4), 251-258.

Dewald, JF, Meijer, AM, Oort, FJ, Kerkhof, GA, \& Bögels, SM. (2010). The influence of sleep quality, sleep duration and sleepiness on school performance in children and adolescents: a meta-analytic review. Sleep Medicine Reviews, 14 (3), 179-189.

Dewald-Kaufmann, J, Oort, F, \& Meijer, A. (2013). The effects of sleep extension on sleep and cognitive performance in adolescents with chronic sleep reduction: an experimental study. Sleep Medicine, 14(6), 510-517.

Durmer, JS, \& Dinges, DF. (2005). Neurocognitive consequences of sleep deprivation. Seminars in Neurology, 25(1), 117-129.
Elliott, GR, \& Feldman, S. (1990). Capturing the adolescent experience. In S Feldman \& GR Elliott (Eds.), At the threshold: the developmental adolescent (pp. 3-15). Cambridge, MA: Harvard University Press.

Gold, M, \& Dahl, R. (2010). Using motivational interviewing to facilitate healthier sleep-related behaviors in adolescents. In M Perlis, M Aloia, \& B Kuhn (Eds.), Behavioral treatments for sleep disorders: a comprehensive primer of behavioral sleep medicine interventions. London, UK: Elsevier Inc.

Gradisar, M, Dohnt, H, Gardner, G, Paine, S, Starkey, K, Menne, A, \& Weaver, E. (2011). A randomized controlled trial of cognitive-behavior therapy plus bright light therapy for adolescent delayed sleep phase disorder. Sleep, 34 (12), 1671-1680.

Gruber, R, Wiebe, ST, Wells, S, Cassoff, J, \& Monson, E. (2010). Sleep and academic success: mechanisms, empirical evidence, and interventional strategies. Adolescent Medicine: State of the Art Reviews, 21(3), 522-541.

Heather, N, Rollnick, S, \& Bell, A. (1993). Predictive validity of the readiness to change questionnaire. Addiction, 88(12), 1667-1677.

Hettema, J, Steele, J, \& Miller, WR. (2005). Motivational interviewing. Annual Reviews Clinical Psychology, 1, 91-111.

Hoelscher, DM, Evans, A, Parcel, G, \& Kelder, S. (2002). Designing effective nutrition interventions for adolescents. Journal of the American Dietetic Association, 102(3), S52-S63.

Iglowstein, I, Jenni, OG, Molinari, L, \& Largo, RH. (2003). Sleep duration from infancy to adolescence: reference values and generational trends. Pediatrics, $111(2), 302-307$.

Knutson, KL, Spiegel, K, Penev, P, \& Van Cauter, E. (2007). The metabolic consequences of sleep deprivation. Sleep Medicine Reviews, 11(3), 163-178.

Kreuter, MW. (2003). Community health promotion ideas that work (2nd ed.). Sudbury, MA: Jones \& Bartlett Publishers.

LaBrie, JW, Quinlan, T, Schiffman, JE, \& Earleywine, ME. (2005). Performance of alcohol and safer sex change rulers compared with readiness to change questionnaires. Psychology of Addictive Behaviors, 19(1), 112-115.

Littner, M, Kushida, C, Bailey, D, Berry, RB, Davila, DG, \& Hirshkowitz, M. (2003). Practice parameters for the role of actigraphy in the study of sleep and circadian rhythms: an update for 2002. Sleep, 26(3), 337-341.

Lowry, R, Eaton, DK, Foti, K, McKnight-Eily, L, Perry, G, \& Galuska, DA. (2012). Association of sleep duration with obesity among US high school students. Journal of Obesity, 2012, 1-9.

Luszczynska, A, \& Schwarzer, R. (2005). Predicting health behaviour: a social cognition approach. In M Conner \& P Norman (Eds.), Predicting health behaviour (pp. 127-170). New York: McGraw-Hill Internationa.

Mercer, PW, Merritt, SL, \& Cowell, JM. (1998). Differences in reported sleep need among adolescents. Journal of Adolescent Health, 23(5), 259-263.

Miller, W, \& Rollnick, S. (2002). Motivational interviewing preparing people for change. New York, NY: The Guildford Press.

Moseley, L, \& Gradisar, M. (2009). Evaluation of a school-based intervention for adolescent sleep problems. Sleep, 32(3), 334-341.

Moyers, T, Martin, T, Manuel, J, Miller, W, \& Ernst, D. (2010). Revised global scales: motivational interviewing treatment integrity 3.1 (1 (MITI 3.1. 1)). Accessed at http://casaa.unm.edu/download/miti3_1.pdf on March 12, 2014.

National Sleep Foundation. (2011). 'Sleep in America' poll: communications technology in the bedroom. from http://www.sleepfoundation.org/sites/ default/files/sleepinamericapoll/SIAP_2011_Summary_of_Findings.pdf.

Noar, SM, Benac, CN, \& Harris, MS. (2007). Does tailoring matter? Meta-analytic review of tailored print health behavior change interventions. Psychological Bulletin, 133(4), 673-693.

Noland, H, Price, JH, Dake, J, \& Telljohann, SK. (2009). Adolescents' sleep behaviors and perceptions of sleep. Journal of School Health, 79(5), 224-230.

Orzech, KM. (2013). A qualitative exploration of adolescent perceptions of healthy sleep in Tucson, Arizona, USA. Social Science \& Medicine, 79, 109-116.

Pawlak, R, \& Colby, S. (2009). Benefits, barriers, self-efficacy and knowledge regarding healthy foods; perception of African Americans living in eastern North Carolina. Nutrition Research and Practice, 3(1), 56-63.

Pizza, F, Contardi, S, Antognini, AB, Zagoraiou, M, Borrotti, M, Mostacci, B, \& Cirignotta, F. (2010). Sleep quality and motor vehicle crashes in adolescents. Journal of Clinical Sleep Medicine: official publication of the American Academy of Sleep Medicine, 6(1), 41-45.

Prochaska, JO, \& Prochaska, JM. (2010). Behavior change. In D Nash, J Reifsnyder, R Fabius, \& V Pracilio (Eds.), Population health: creating a culture of wellness. USA: Jones \& Bartlett Learning.

Prochaska, JO, \& Velicer, WF. (1997). The transtheoretical model of health behavior change. American Journal of Health Promotion, 12(1), 38-48. 
Reynolds, AC, \& Banks, S. (2011). Total sleep deprivation, chronic sleep restriction and sleep disruption. Human Sleep and Cognition: Basic Research, 185, 91-104.

Riemsma, RP, Pattenden, J, Bridle, C, Sowden, AJ, Mather, L, Watt, IS, \& Walker, A.

(2003). Systematic review of the effectiveness of stage based interventions to promote smoking cessation. BMJ, 326(7400), 1175-1177.

Rimer, BK, \& Kreuter, MW. (2006). Advancing tailored health communication: a persuasion and message effects perspective. Journal of Communication, 56 (s1), S184-S201.

Rollnick, S, \& Miller, WR. (1995). What is motivational interviewing? Behavioural and Cognitive Psychotherapy, 23, 325-334

Rollnick, S, Heather, N, Gold, R, \& Hall, W. (1992). Development of a short 'readiness to change'questionnaire for use in brief, opportunistic interventions among excessive drinkers. British Journal of Addiction, 87(5), $743-754$.

Salmon, J, Booth, ML, Phongsavan, P, Murphy, N, \& Timperio, A. (2007). Promoting physical activity participation among children and adolescents. Epidemiologic Reviews, 29(1), 144-159.

Saxvig, IW, Wilhelmsen-Langeland, A, Pallesen, S, Vedaa, $\varnothing$, Nordhus, $\amalg_{1}$, \& Bjorvatn, B. (2013). A randomized controlled trial with bright light and melatonin for delayed sleep phase disorder: effects on subjective and objective sleep. Chronobiology International, 37(1), 72-86.

Sohl, SJ, \& Moyer, A. (2007). Tailored interventions to promote mammography screening: a meta-analytic review. Preventive Medicine, 45(4), 252-261.

Treasure, J. (2004). Motivational interviewing. Advances in Psychiatric Treatment, 10 (5), 331-337

Watts, FN, East, MP, \& Coyle, K. (1995). Insomniacs' perceived lack of control over sleep. Psychology and Health, 10(2), 81-95.

Weinstock, MA, Rossi, JS, Redding, JA, Maddock, JE, \& Cottrill, SD. (2000). Sun protection behaviors and stages of change for the primary prevention of skin cancers among beachgoers in southeastern New England. Annals of Behavioral Medicine, 22(4), 286-293.

Wilhelmsen-Langeland, A, Saxvig, IW, Pallesen, S, Nordhus, IH, Vedaa, $\varnothing$, Lundervold, AJ, \& Bjorvatn, B. (2013). A randomized controlled trial with bright light and melatonin for the treatment of delayed sleep phase disorder effects on subjective and objective sleepiness and cognitive function. Journal of Biological Rhythms, 28(5), 306-321.

doi:10.1186/2050-7283-2-6

Cite this article as: Cassoff et al:: Evaluating the effectiveness of the Motivating Teens To Sleep More program in advancing bedtime in adolescents: a randomized controlled trial. BMC Psychology 2014 2:6.

\section{Submit your next manuscript to BioMed Central and take full advantage of:}

- Convenient online submission

- Thorough peer review

- No space constraints or color figure charges

- Immediate publication on acceptance

- Inclusion in PubMed, CAS, Scopus and Google Scholar

- Research which is freely available for redistribution 